\title{
GC-MS Analysis of Volatile Plant Secondary Metabolites
}

\author{
Elena E. Stashenko and Jairo René Martínez \\ Industrial University Santander, \\ Colombia
}

\section{Introduction}

Knowledge of the identity and relative amounts of the volatile substances released by plants is of great importance to several fields of basic and applied research in biology, chemistry and may other disciplines. Obtaining this knowledge requires overcoming many analytical challenges posed by these complex mixtures, because they normally present large variations in component amounts, chemical structures and functionalities. Gas chromatography (GC) is recognized as the most suitable technique to find out how many components and in what proportion there are in a complex mixture of volatile compounds. When it is coupled to mass spectrometry (GC-MS), additional information arises about each separated compound molecular mass, elemental composition (when high resolution mass spectrometry is used), functional groups, and in certain cases, molecular geometry and spatial isomerism. This chapter covers the most determinant factors which affect biogenic volatile compound (BVOC) GC-MS analysis. Sample preparation, chromatographic separation and mass spectrometry are the main parts explained within the framework of BVOC analysis and practical examples of their application to flower scent and essential oil analysis are presented.

\section{Isolation techniques}

The process employed for plant volatiles isolation strongly determines the final outcome of the analysis. The number of compounds to be found and their relative amounts depend on how the sample was prepared, what extraction technique was employed, whether any clean up step was included, how potential interferences were removed and to what extent the final extract was concentrated. The right selection of extraction technique involves the consideration of aspects such as: (1) the nature of the matrix (origin, aggregation state, homogeneity, stability) and of the analyte (volatility, polarity, reactivity, thermal stability); (2) the purpose of the analysis (qualitative, quantitative); (3) the need to confirm the chemical structure of the analyte (identification using spectroscopic techniques); (4) how urgently the results are needed (for example, to determine the nature of a person's intoxication); (5) the potential legal implications of the results (forensic, environmental analyses, doping control) and lastly, (6) it is important to know whether the extraction method is well known and is already standardized or it should be established, optimized and validated. GC-MS analysis requires the previous removal of substances which are not 
compatible with this technique (ions, gums, polymers and other macromolecules) and an extract of sufficient concentration to have analyte concentrations above the limits of detection/quantitation of the corresponding GC-MS method (Koning et al., 2009). Extraction methods could be classified as: I. Distillative methods, II. Extractive methods and III. Headspace methods. Certain sui generis techniques may combine methods from different groups, as in the case of simultaneous distillation-solvent extraction (SDE) (Chaintreau, 2001).

\subsection{Distillation methods}

The isolation of essential oils or volatile fractions for final products, from vegetal material, by means of extractive distillation, may take place under 3 main configurations: (1) Steam distillation (SD); (2) Hydrodistillation (HD), or (3) Water-vapor distillation. Volatile mixtures may be subjected in industrial processes to distillation at reduced pressure in special columns (molecular distillation), in order to isolate or increase the concentration of a particular constituent. However, molecular distillation and related techniques are not appropriate for trace-level components isolation or study. Extracts or volatile fractions isolated by SD, HD or SDE constitute mixtures suitable for direct GC-MS analysis. A drying step (with anhydrous sodium sulfate) may be the only treatment required before their injection into the gas chromatograph. With the aim of increasing extraction efficiency while reducing distillation time, during the last 25 years there has been an increased use of microwave radiation as a heat source (Kingston \& Jassie, 1988; Kingston \& Haswell, 1997). Microwave-assisted extractions (MAE) employ water or an organic solvent to obtain extracts from solid samples (vegetal material, soil, tissues, etc.) (Rice and Mitra, 2007).

\subsection{Extraction procedures}

The second family of isolation techniques makes use of solubility, adsorption or absorption differences to induce the mass transfer from the vegetal material to a stream or static phase of an extractive agent. Adsorption or absorption-driven extraction processes involve porous polymers (PDMS, Tenax, Porapak, Chromosorb, synthetic resins) or microporous solids (charcoal, silica gel, alumina, molecular sieves). Solubility-driven processes are employed the most. Their main example is liquid extraction, which can be performed in either continuous or batch modes. Careful solvent selection (polarity, boiling point, dielectric constant, H-bond ability, availability, cost, etc.) is the most important determinant of extraction yield and selectivity. Extract cleanup and concentration are frequently required prior to instrumental analysis. Despite the problems associated with liquid extraction (emulsion formation, long extraction times, difficult automation, waste disposal, potential cross-contamination), the number of published research works in which liquid extraction is employed, has continued growing during the last decade (Mustafa \& Turner, 2011; Zhang \& $\mathrm{Li}, 2010)$. Solid-phase extraction (SPE), which appeared around 40 years ago, has been implemented as a competitive alternative to liquid extraction (Fritz, 1999; Thurman \& Mills, 1998). The amount of solvent required is reduced substantially and extraction, cleanup and concentration are combined in a single step. Besides, SPE can be automated to increase sample throughput, as exemplified by several commercial devices which include a direct connection with the chromatograph. Despite the high cost of the initial investment, there has been an intense growth in the application of supercritical fluid extraction (SFE) during the 
last decade. Extraction selectivity in SFE can be modified by means of operational parameters because analyte solubility depends on supercritical fluid density (pressure, temperature) and the presence of modifier agents (co-solvents) (Westwood, 1993; Wenclawlak, 1992; Huang et al., 2009). When SFE is used with plant material, a cleanup step is required before GC-MS analysis, in order to remove fat, pigments, waxes, or other highmolecular weight compounds. Soxhlet extraction is one of the oldest extractive methods and has been one of the most employed approaches in plant material extraction. However, its low selectivity imposes the need for further extract cleanup steps. A very successful alternative method is accelerated solvent extraction (ASE), in which the use of higher temperature and pressure permit higher selectivity, with important reductions in extraction time and amount of solvent employed. ASE permits the combination of extraction, cleanup and concentration in a single step, with automated operation and the possibility of direct coupling with the GC-MS instrument (Zuloaga et al., 1998; Gan et al., 1999).

\subsection{Headspace sampling}

A true "green revolution" in sample preparation techniques has taken place in the last 2 decades thanks to the introduction of solid-phase microextraction (SPME) (Scheppers, 1999; Wang et al., 2002). In SPME, target analytes are extracted and concentrated on the polymeric coating of a silica fiber under 3 alternative setups: (1) headspace sampling, which consists in the exposure of the SPME fiber to the sample's vapor phase; (2) direct immersion of the SPME fiber into a fluid sample, and (3) use of a protective membrane around the SPME fiber when it is exposed to the sample. SPME is very compatible with GC-MS and there are commercial devices to perform the SPME sampling process and the direct desorption of the SPME fiber into the injection port of the chromatographic system in a programmable manner. The ionic strength of the sample, the SPME fiber exposure temperature and time, the intensity of sample agitation, and the nature of the SPME fiber coating are variables that the experimenter can modify to change the selectivity of the SPME method and the recovery. Additionally, target analyte derivatization in the sample matrix or on the SPME fiber is a valuable tool to enhance selectivity and sensitivity in an analytical SPME method (Stashenko \& Martinez, 2004; Araujo et al., 2008). According to their classical arrangements, the headspace sampling methods are classified into static (S-HS) and dynamic (D-HS) headspace methods. Large capacity sorption techniques, developed in the last 20 years, share features of both setups (Bicchi et al., 2004). The resultant volatile fractions are amenable to direct GC-MS analysis because the vapor phase does not contain macromolecular or ionic interfering species that may be present in the matrix. S-HS is normally employed in cases where the target analyte is present in relatively high amounts and no concentration is required before instrumental analysis. D-HS is preferred in cases where the target analyte is present at trace levels (ppt, ppb) because this sampling method permits enrichment of the collected volatile substances. Basically, the method consists of a purge of the vapor phase of the sample with a stream of an inert carrier gas which removes the VOC's. They are subsequently removed from this gas by dissolution in a solvent, by cryo-trapping, adsorption or absorption on a highly porous solid material. The final extract is obtained by solvent evaporation (Kuderna-Danish apparatus or removal with a gas flow) in the first case, or thermal desorption, or solvent elution in the other instances. The use of the vapor phase above the sample (headspace) as the interface with the extracting agent has many advantages from the analytical viewpoint, because many possible interferences are 
prevented from entering the extract. In natural products studies headspace sampling has permitted in vivo collection of the volatile substances around the whole plant, or directly at its parts (Tholl et al., 2006).

\subsection{Miscelaneous techniques}

New methods for microscale sampling have emerged in recent years after the detection of certain limitations in the application of SPME in different fields (Koning et al., 2009). One of the main improvements sought has been an increase in the concentration capacity of tracelevel target analytes. In several cases, a concentration capacity superior to that of SPME is achieved using a larger volume of the sorption phase. In the inside needle capillary adsorption trap (INCAT), a polymeric layer coats the inner wall of a syringe needle or this volume is filled with charcoal (Musshoff et al., 2003 ). A related technique, headspace solidphase dynamic extraction (HS-SPDE), uses a gas-tight syringe whose inner walls have been coated with a polymer such as polydimethylsiloxane (PDMS), in which the analytes will deposit when the syringe barrel is pushed and pulled repeatedly over the sample (Bagheri et al., 2009). The number of push-pull cycles determines the amount of accumulated analytes in the polymer. Just as in SPME, the analytes are afterwards released by thermal desorption at the injection port of the chromatograph. Stir bar solid-phase extraction (SBSE) and sorption tape extraction (STE) (Bicchi et al., 2005), are examples of sampling techniques in which a much larger volume of sorption phase is used to increase concentration capacity. In SBSE, a magnetic stir bar is coated with at least one type of sorption polymer (PDMS, polyethyleneglycol). Analytes are absorbed or adsorbed in the polymer coating upon stirring the sample solution with this magnetic bar, which is later on transferred to a heating device in order to release the analytes directly into the injection port of the chromatograph. STE is a very simple technique which can be used for in vivo sampling. In STE, a thin PDMS film is placed in close proximity or in contact with a plant part for a fixed period of time. Sampled analytes are then removed by thermal desorption. Liquid-phase microextraction (LPME) employs a hanging solvent drop or the solvent film formed inside a syringe to trap the analytes (Shen \& Lee, 2003). Solvent type, syringe size and the number of push-pull cycles are the main operational parameters normally employed to improve the selectivity and recovery of the technique.

\section{Gas chromatographic methods}

Four fundamental blocks comprise a chromatographic system: (1) sample application system (injector); (2) mixture separation system (column); (3) detection system responsive to the analytes eluting from the column (detector), and (4) data system. Analytical quality rests on the combined performance of all basic blocks. For example, the injection system must transfer the sample into the chromatographic column in a quantitative manner, without discrimination due to molecular weight or component volatility and without chemical alteration of any constituent substance. This entrance door into the column must remain clean, contaminant-free, inert and without leaks. Component separation is achieved when the operational parameters (temperature, mobile phase velocity or polarity, pressure) and the column characteristics (length, internal diameter, stationary phase chemical nature and thickness) are such that the distribution constants (between stationary and mobile phases) of all mixture components are different. The detector response (signal) results from the 
measurement of a physical property which depends on the amount of analyte molecules emerging from the column (ionic current, thermal conductivity, fluorescence, refractive index, photon emission, etc.). The direct relationship between detector signal intensity and analyte amount constitutes the basis of the chromatographic determination and addresses the question of how many components are there in a mixture and in what proportion they are found (quantitative analysis).

\subsection{Chromatographic separation}

The mixture components are separated in a chromatographic column as a result of their distribution between a mobile and a stationary phase. One of the most relevant performance parameters of a chromatographic column is its resolution, which is its ability to separate compounds with very similar distribution constants. Chromatographic resolution is a function of several operational parameters. Column dimensions (length, internal diameter and stationary phase thickness) constitute an important set of resolution modifiers. The higher the number of mixture components and their structural similarity, the longer the chromatographic column required to achieve their separation. However, for the same purpose, an alternative variation is the reduction of column diameter. Increasing column length notoriously extends the analysis time. While a factor of 2 in column length doubles its resolution, a factor of 0,5 in internal diameter increases resolution 4 times. Micro-bore columns $(0,1$ and $0,05 \mathrm{~mm}$ internal diameter), used in "fast chromatography", permit the separation of complex mixtures in experiments which lasts seconds instead of hours. However, the reduction in column diameter causes a dramatic decrease in sample capacity. Thus, trace-level components could not be determined using fast chromatography. Therefore, the selection of column length and diameter is a compromise between analysis time and the required resolution and sensitivity (Robards et al., 1994; Barceló, 2008). Stationary phase thickness is selected according to sample volatility. Mixtures of highly volatile compounds require columns with higher stationary phase thickness $(5 \mu \mathrm{m})$, while compounds with high boiling points, such as steroids, are analyzed using columns with thinner coating $(0,25 \mu \mathrm{m}$ or less). Higher stationary phase thickness enhances compound retention, which generates the need for higher column temperature in order to accelerate compound elution. This in turn causes more stationary phase bleeding, which affects the chromatographic profile. Stationary phase polarity is selected according to sample type, its composition and the polarity of the substances to be analyzed. In columns with non-polar stationary phases, e.g. poly(dimethylsiloxanes), compounds elute following their boiling points. In columns with polar stationary phases, e. g. poly(ethyleneglycol), retention times and elution order are determined by intermolecular forces (between analyte and stationary phase polymer) and the dipole moments of the substances. The complete separation of complex mixtures with both polar and non-polar components frequently requires 2 chromatographic columns with orthogonal polarity (polar and non-polar stationary phases). This is the approach regularly employed in essential oil analysis. Figure 1 presents chromatographic profiles of the essential oil isolated from African lemon (Swinglea glutinosa) fruit peel, analyzed in 2 columns, with poly(ethyleneglycol) and poly(dimethylsiloxane) stationary phases, and using 2 types of injection conditions. Large retention time differences are apparent between the chromatograms obtained on different stationary phases (Figures 1A, 1B). For example, the retention time of citronellal (peak e), a monoterpenic aldehyde, almost doubles when the stationary phase is changed from non-polar to polar. Since 
retention times depend on column dimensions, stationary phase polarity, oven temperature and carrier gas flow, the comparison of retention times obtained with columns of different stationary phase requires the use of retention indices (Zellner et al., 2008). They are calculated from the comparison of the retention times of a homologous $n$-alkanes mixture with those of the sample components, when both are analyzed under the same chromatographic conditions (temperature, gas flow), on columns with different stationary phase (vide infra). Retention indices are collected into databases to be used as reference parameters to aid in compound identification.

The amount of sample transferred into de chromatographic column is another factor which affects the analytical results. Solutions with relatively large amounts of components should be admitted into the chromatograph using split injection, in which only a fraction of the injected amount is directed to the column. When the target analytes are present at trace levels, splitless injection is used, in order to transfer the entire injected amount into the column. Figure 1 (C, D) illustrates the large difference in the number of detected components when the same amount of a solution of Swinglea glutinosa essential oil is injected in splitless and split (1:30) modes. The splitless mode involves the slow transfer (1 $\mathrm{mL} / \mathrm{min})$ of the sample into the chromatographic column, through the hot $\left(\sim 300{ }^{\circ} \mathrm{C}\right)$ injection zone, which may cause thermal degradation of certain components. The trace in Figure $1 C$ shows strong sesquiterpene coelution in the 27-33 min region, owing to structural similarity and possible isomerization at the injection port. Pulsed splitless injection is a modification in which carrier gas pressure is increased just during the injection, in order to substantially reduce the exposure time of heat sensitive substances to the hot areas.
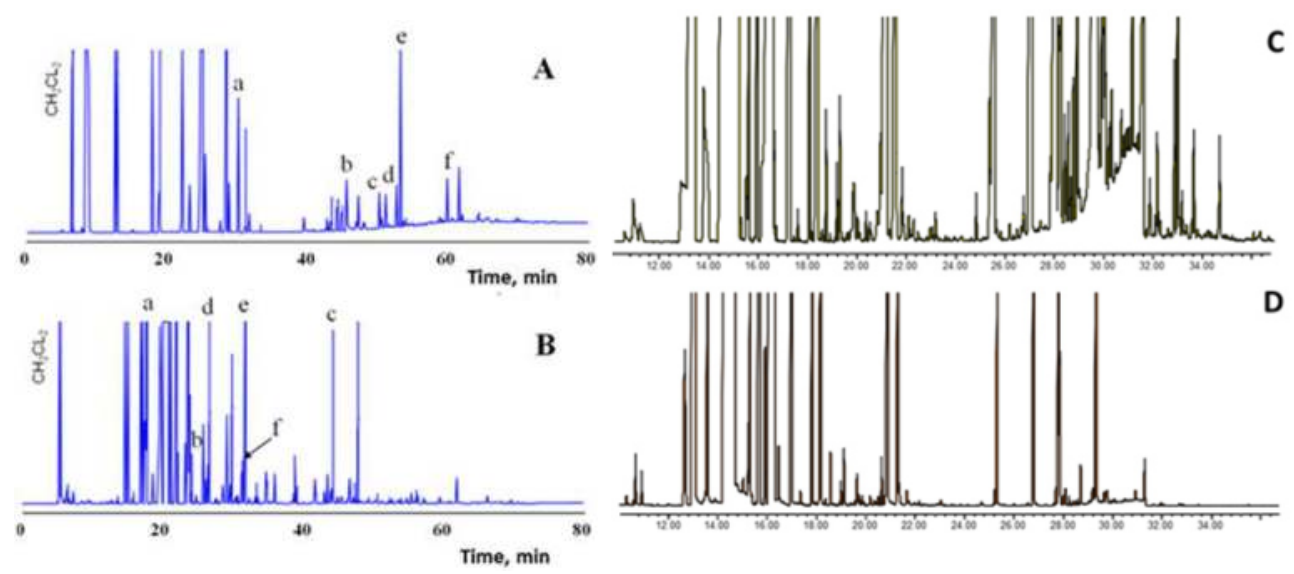

Fig. 1. Swinglea glutinosa essential oil chromatograms. A. Acquired on a chromatographic column with polar stationary phase (DBWAX, $60 \mathrm{~m} \times 0,25 \mathrm{~mm} \times 0,25 \mu \mathrm{m}$ ). B. Column with non-polar stationary phase (DB-1, $60 \mathrm{~m} \times 0,25 \mathrm{~mm} \times 0,25 \mu \mathrm{m})$. Flame ionization detector, split ratio 1:30, oven temperature program: $40^{\circ} \mathrm{C}(5 \mathrm{~min}) @ 3{ }^{\circ} \mathrm{C} / \mathrm{min}$ to $250{ }^{\circ} \mathrm{C}(5 \mathrm{~min})$. a p-Cymene; $\mathrm{b}$ - Linalool; $\mathrm{c}$ - $\alpha$-Bergamotene; $\mathrm{d}$-cis-Allocymene; e - Citronellal; $\mathrm{f}$ - Neral. $\mathrm{C}$. Splitless injection. D. Split (1:30) injection. Injection volume - $1 \mu \mathrm{L}$ (20\% in dichloromethane). Mass selective detector (MSD, EI, $70 \mathrm{eV})$. Acquisition mode: full scan $(\mathrm{m} / \mathrm{z} 30-400)$. 
On-column injection is another admission mode, which prevents component discrimination due to volatility or molecular weight. The sample is applied directly into the column head. This might be seen as an ideal injection, but with a large number of samples there is the risk of severe column contamination. This is caused by non-volatile sample components which deposit inside the column and eventually clog it. Split/splitless injection ports include a liner just before the column, to act as a filter for these interfering substances. In the case of on-column injection, a pre-column, or retention gap, which is a short capillary with no inner coating, is used for this purpose.

\subsection{Detection systems}

A quantitative and reproducible signal is the main characteristic expected from a detection system. The chromatogram is a plot of the detector signal as a function of time. The chromatographic peak heights or areas (used preferably) are the basis for analyte quantitation, after correcting for the different response that the detector may afford after its interaction with each individual sample component, according to its chemical nature (Novák, 1988). Detectors which generate a signal for each and every eluting substance (except for the carrier gas) are classified as universal. The thermal conductivity detector (TCD) (Kaanta et al., 2010), the infrared detector (IRD) (Wang \& Edwards, 2007), the mass selective detector (MSD) operating in full scan mode (Hayward \& Wong, 2009) and the flame ionization detector (FID) (de Souza \& de Andrade, 2009) belong to this group, although the FID is quasi-universal for not being responsive to permanent gases, water, or compounds without carbon-containing groups. Selective detectors constitute a large group of GC detectors. The nitrogen and phosphorus selective detector (NPD) emits a selective response to all compounds with nitrogen or phosphorus in their structure (Amvrazy \& Tsiropoulos, 2009). The flame photometric detector (FPD) releases a signal only in the presence of compounds with sulfur or phosphorus in their structure (Hayward \& Thurbide, 2009). The atomic emission detector (AED) expands the domain of chemical elements that can be registered in the eluting substances, to the extent of performing their elemental analysis (Campillo et al., 2010). The electron capture detector (ECD) provides a highly sensitive response to substances with electronegative groups (nitro, halogens, etc.), although it is not very selective (Abhilash et al., 2009). The MSD operated in selective ion monitoring (SIM) mode affords a very selective signal based on the partial ion current produced by a fragment or group of fragments in the mass spectrum of the target analyte. The thermal energy analyzer (TEA) generates a signal for those substances with nitro groups in their structure (Yinon, 1995). This is valuable in the analysis of organic explosive residues or of Nnitrosamines in food. Olfactometric detectors are of great interest in plant volatile analysis. In combination with conventional detectors (TCD, FID, MSD), they permit to go beyond quantification and identification of an aromatic mixture, to perform the organoleptic evaluation of all substances emerging from the chromatographic column (Sasamoto \& Ochiai, 2010). The study of semiochemicals, for example, pheromones, involves the use of live detectors, in which the antenna of an insect is part of an electronic circuit which provides a highly specific signal to the pheromones relevant to that insect species (D'Alessandro \& Turlings, 2006). Unsaturated and aromatic molecules may be differentiated from other mixture components when the photoionization (PI) detector is used (Lewis et al., 2010). Chemiluminiscense detectors are highly sensitive and selective to nitrogen- or suphur-containing substances (Shearer, 1992). The great limitation of conventional detectors 
stems from their incapability to unequivocally identify a problem substance. Absolute or relative retention times and certified standards are employed for the presumptive or tentative substance identification based on GC data from conventional detectors. The confirmatory identification of a substance in a complex mixture necessarily requires a "fingerprint", that is, its spectral signature. The complementary information is provided by the mass spectrum, which presents a unique combination of charged molecular fragments (ions) produced by the fragmentation or dissociation of the target analyte molecules after their ionization. This synergistic match of screening data with confirmatory spectral information is achieved using the combination GC-MSD.

\subsection{Retention indices}

In the middle of the previous century, with the aim of increasing the confidence level of the comparison of chromatographic retention data, Hungarian scientist E. Kovàts introduced a retention index system which is known as Kovàts indices. They are based on the measurement of retention times relative to those of a homologous $n$-paraffin series run under the same experimental conditions as the sample (Kovàts, 1958, 1965). Due to the state of technical development at the time, the chromatographic separations were performed at constant temperature (isothermal regime). The possibility of reliably programming the chromatographic oven temperature was implemented in commercial equipment several years later. Under isothermal conditions, the logarithm of the retention time increases with the number of carbon atoms of the paraffin. E. Kovàts assigned n-paraffin retention index values (KI) equal to $100 \mathrm{n}$ : 500 corresponds to pentane, 600 to hexane, 700 to heptanes, etc. The isothermal retention indices (KI) are calculated according to equation (1), where $n$ is the number of carbon atoms in the n-paraffin eluting (with retention time $t_{R n}$ ) before the compound of interest (with retention time $t_{\mathrm{Rx}}$ ). $\mathrm{N}$ is the number of carbon atoms of the $\mathrm{n}$ paraffin eluting (with retention time $t_{\mathrm{RN}}$ ) after the compound of interest.

$$
K I=100 n+100 \frac{\log t_{R x}-\log t_{R n}}{\log t_{R N}-\log t_{R n}}
$$

Retention indices are expected to be independent of most experimental conditions (temperature, carrier gas flow, and most importantly, column dimensions). However, temperature dependence is noticed as well as a clear dependence on stationary phase polarity. Most samples are mixtures of many components with large differences in vapor pressure and molecular weight, which cannot be analyzed in reasonable time with sufficient resolution, using isothermal conditions. The chromatographic analysis of complex mixtures requires programming the oven temperature to mix isothermal periods with periods of heating at a constant rate. This causes $n$-paraffin elution to be linear, not logarithmic. Van den Dool and D. J. Kratz modified equation 1 to calculate linear retention indices (LRI), which are massively employed today according to equation 2 (van den Dool \& Kratz, 1963).

$$
L R I=100 n+100 \frac{t_{R x}-t_{R n}}{t_{R N}-t_{R n}}
$$

Although isothermal (KI) and linear (LRI) retention indices have close values, they are not identical. Therefore, when reporting retention indices it is important to indicate what type of index was calculated. LRI actually depend on the initial column temperature, the heating rate, stationary phase polarity and its state (contamination, activity, and fabricant). In fact, 
published retention data have an appreciable dispersion, even for the same stationary phase (Babushok \& Zenkevich, 2009). This reduces the reliability of substance identification based solely on retention index matching. Standardization of chromatographic conditions for retention index determination would undoubtedly lead to higher reproducibility and confidence on their use in compound identification. In order to reduce the chance of accidental coincidences, it is highly recommended to determine retention indices on orthogonal (polar and non-polar) stationary phases. This way, the presumptive identification is obtained only when the unknown substance and a standard have very similar retention indices on both types of stationary phase. The confirmatory identification requires the match of a third parameter, their mass spectra.

\subsection{Multidimensional and comprehensive GCxGC analysis}

The frequent coelution of substances with extremely close distribution constants represents the largest challenge in complex mixture separation. Multidimensional chromatography permits the use of a second column to separate the peaks of partially or completely coeluted substances. By means of the "heart cutting" operation, pneumatic commuting valves (nowadays microfluidics devices are available to perform this switching) direct the eluting flow from one to the other column during a fixed time period. Multidimensional chromatography requires at least 2 detectors and may have configurations with 3 columns in the same or separate chromatographic ovens. The idea of using a second column has been extended to transfer not just a portion of the eluting flow, but every single segment during the whole chromatographic run. The resulting technique is known as total or complete chromatography, abbreviated GCxGC. Two columns with orthogonal stationary phases are connected by means of a modulator, which collects the eluting flow from the first column during a short time period and transfers it to the second one, which should be short enough to be transited by the transferred portion before the next one is admitted (Marriot et al., 2001). In contrast with multidimensional chromatography, GCxGC requires only 1 detector. The columns may be in the same or separate ovens. There are different approaches to perform the fractionation of the flow from the first column (1D, $25-30 \mathrm{~m}$ ) into multiple; consecutive slices which are transferred with or without cryoconcentration to the second column (2D, micro bore, $1 \mathrm{~m}$ ). The modulation time should not be longer than the elution time in the second column. This is the main reason for using a fast chromatography column (short, small diameter) as the second column, in which elution times of a few seconds are regularly obtained. Since this column is connected to the detector, this should have a very high speed of data collection and processing (MSD, FID, $\mu$-ECD). The best choice for fast response is the time of flight mass analyzer (TOF), although it has a relatively high cost (Mondello et al., 2008; Adahchour et al., 2008).

\section{Gas chromatography coupled to mass spectrometry}

A very powerful combination results from the union of the high resolution capacity of gas chromatography with the identification capabilities of mass spectrometry. The resulting data have a tri-dimensional nature, from which retention times, chromatographic areas and mass spectra can be obtained for every single component of a complex mixture. The mass selective detector may operate in 3 acquisition modes (universal, selective, or specific) which facilitate the detailed characterization of complex mixtures such as those normally isolated 
from plants. The following sections present several aspects of the GC-MS technique which are important in the analysis of plant volatile compounds.

\subsection{Ionization techniques}

The essence of mass spectrometry stems from the ionization of molecules, accompanied or not by their subsequent dissociation or fragmentation. Molecular ionization may take place in the vapor phase (which requires volatilizable and thermally stable molecules) or in condensed phase (for very polar, or thermo labile, non-volatile or high-molecular weight substances). Molecular ionization requires energy, which may be supplied by accelerated or thermal electrons, by photons (photoionization, crown discharge, laser beam), by accelerated atoms or ions, by a high gradient of an electrostatic field, or by thermal impact. The ionization of vapor-phase molecules may be carried out with various techniques. Electron ionization (EI), chemical ionization (CI), and field ionization (FI) are the most common approaches. EI is the most employed ionization technique for small molecules. Chemical ionization with positive (PICI) or negative (NICI) ions is an analytic complement that is employed when the mass spectra obtained with EI do not contain molecular ions. Electrons are excellent ionization agents for organic molecules. They are easy to generate (just heating a tungsten or rhenium filament) and their energy can be regulated by means of the applied voltage between filament (cathode) and anode. For most organic molecules, the maximum ionization efficiency is obtained with $50-60 \mathrm{eV}$ bombarding electrons. Standard mass spectra are obtained with $70 \mathrm{eV}$ electrons because higher repeatability and reproducibility are obtained. Mass spectral libraries are built with spectra obtained by ionization using electrons with $70 \mathrm{eV}$ of energy. This facilitates the comparisons among spectra obtained in different spectrometers and those of different databases. Ionization efficiency depends not only on the energy of the bombarding electrons, but also on the pressure at the ionization chamber or ion source $\left(10^{-5}-10^{-6}\right.$ Torr), and on their contamination level. Column bleeding, non-volatile interfering substances or their fragments form deposits on the surface of parts of the ionization chamber. This contamination and system leaks (air, water) cause sensitivity decrease as a consequence of the lower ionization efficiency that they ensue.

\subsection{Mass analyzers}

Mass analyzers separate ions according to their $\mathrm{m} / z$ ratio. Nobel prize winner Wolfgang Paul invented the quadrupole filter (Q) and the quadrupole ion trap (IT), which are the most common analyzers used in GC-MS to determine $\mathrm{m} / \mathrm{z}$ ion ratios (Hübschmann, 2009; Fontana et al., 2010). In recent years the use of the time of flight analyzer has grown considerably (Marsman et al., 2008). Although its cost remains high, there has also been a moderate increase in the applications of Fourier transform ion-cyclotron resonance mass spectrometry (FT-ICR), due to the high resolution it provides. The magnetic sector analyzer was the most employed type during the development of mass spectrometry (McMaster \& McMaster, 1999). In the quadrupole mass analyzer the ions formed at the ionization chamber are collimated and accelerated by means of a series of electrodes (with accelerating potentials of $5-100 \mathrm{~V}$ ) which lead them into the space between 4 metallic bars which constitute the quadrupole. Direct and alternating (radiofrequency) voltages are applied to the 4 bars. The resulting electric field determines the complex oscillatory trajectory to be followed by the 
incoming moving ions. For a particular combination of DC and alternating RF voltages there will be a particular $\mathrm{m} / \mathrm{z}$ value for which the trajectory will be along the central axis of the quadrupole. All other $\mathrm{m} / z$ values will have divergent trajectories which will make the ions collide with the quadrupole bars. The systematic variation of the applied voltages permits a continuous scan of an interval of $\mathrm{m} / \mathrm{z}$ values, so that eventually every incoming ion has the appropriate $\mathrm{m} / \mathrm{z}$ value to cross the quadrupole filter and reach the detector (normally, an electromultiplier). Since a scan of the $\mathrm{m} / \mathrm{z}$ interval $(50-350 \mathrm{~m} / \mathrm{z}$ is typical for VOCs) lasts a fraction of a second, scans are continuously repeated. The value of the detector signal associated with each $\mathrm{m} / \mathrm{z}$ value scanned is stored in the data system after its corresponding electronic amplification. The chromatographic profile in GC-MS is the graphical representation of time variation of the total ion current. The total ion current is a value obtained for every scan after the detector signals for every $\mathrm{m} / \mathrm{z}$ value in the scan are added. A chromatographic peak is thus a set of consecutive scans whose total ion currents increase, reach a high value (modal value), and decrease to a value very close to that of the first scan in the set. For each scan, the graphical representation of detector signal versus $m / z$ values constitutes the acquired mass spectrum. GC-MS data systems permit a quick and easy examination of chromatographic profiles and their associated mass spectra. Chromatographic peak purity can be determined by comparing the mass spectra of the scans in a peak. High spectral similarity indicates that the peak effectively corresponds to a single substance, while the detection of different spectral patterns indicates coelution. A metallic ring and 2 end caps with a hyperbolic shape are the basic components of a quadrupole ion trap. Ions are admitted into the trap as a result of an electrostatic pulse. The size of the ion trap (ring radius), the frequency of the voltage applied and the amplitude of the DC voltage modulate the stability of a particular ion in the trap. Collisions with helium ( $\sim 1$ mTorr) present in the ion trap reduce the kinetic energy of the ions and help to focus their trajectories in the ion trap center. Ions of a given $\mathrm{m} / \mathrm{z}$ value form a packet and are ejected as such when the amplitude of the applied radiofrequency is changed. Just as with the $Q$ analyzer, the mass spectrum results from the systematic change of the applied voltage to sequentially eject ion packets from low to high $m / z$ values.

\subsection{Acquisition modes}

The MSD may be operated as a universal, a selective, or a specific detector, depending on how the information is acquired. In full scan mode, spectra are obtained for all sample components as they elute from the chromatographic column. These spectra are the basis for substance identification. Scan speed depends strongly on the type of mass analyzer in use (quadrupole, ion trap, time of flight, or magnetic sector) and on the $\mathrm{m} / \mathrm{z}$ range. This mass range is established according to the sample nature, that is, the range of molecular weights of its components. The low mass value for aliphatic compounds, alcohols, and amines, may be set between 30 and $40 \mathrm{Da}$. Lower values are not recommended because they correspond to background signals. For aromatic structures the low mass may be set at $m / z 50$. The high mass of the full scan should correspond to the molecular weight of the heaviest sample component, plus 40 - 50 units. If a GC-MS analysis of low-molecular weight volatile compounds employs too wide an interval, e.g. $\mathrm{m} / \mathrm{z} 30$ - 550, the number of spectra gathered per unit time will be small. This affects the quality, reproducibility and reliability of the analytical data. For example, a typical essential oil consists of monoterpenes (Mol. Wt. 136), oxygenated monoterpenes (Mol. Wt. 150, 152, 154), sesquiterpenes (Mol. Wt. 204) and 
oxygenated sesquiterpenes (Mol. Wt. 220, 222). For efficient data gathering, the chromatographic run may be split into various intervals corresponding to the retention times of the different substance classes and within these intervals, the mass scan range used could be defined according to the typical molecular weights of the substance class. When instead of a mass interval, a discrete set of $\mathrm{m} / \mathrm{z}$ values is used with the mass analyzer, the MSD acts as a selective or a specific detector. For example, the diagnostic ion in alkylbenzene mass spectra is the tropylium ion, at $m / z$ 91, which frequently is also the base peak of the spectrum. In the chromatographic analysis of a complex mixture it is common to find instances of coelution. If only $\mathrm{m} / \mathrm{z} 91$ ions are allowed to pass the mass analyzer, a simplified chromatographic profile (partial ion current) will be obtained, corresponding to only those substances (alkylbenzenes) whose mass spectrum contains a signal at $\mathrm{m} / \mathrm{z} 91$. These chromatographic profiles are called mass fragmentograms. In this example, the MSD operated in the selected ion monitoring (SIM) mode was selective to the family of substances whose structures possess the benzyl fragment, which generates the diagnostic $\mathrm{m} / \mathrm{z} 91$ ion, common to all the spectra in the family. The SIM mode of operation is used not only because of its highly selective character, but also due to the much higher sensitivity achieved by acquiring more data per unit time as a consequence of reading a small number of $m / z$ values rather than an interval of several hundred units. The selection of ions to be monitored should attend the following criteria: (1) their signal should be higher than 30\%; (2) their mass should be relatively high, since ions with low mass are common to many substances; (3) the selected ion should be structurally representative of the molecule or set of molecules of interest and, (4) the selected ion(s) should not coincide with background signals $(\mathrm{m} / \mathrm{z} 17$, $18,28,32,40,43,44)$ or with column bleeding fragments $(\mathrm{m} / \mathrm{z} 73,147,207,281,355)$, septum thermal degradation products $(\mathrm{m} / \mathrm{z} 149)$, or other contaminants. In environmental and forensic analysis it is frequent to monitor 3 ions. One ion is used for quantitative purposes and the other 2 are qualifier ions, distinctive of the substance of interest. An interesting feature that is possible with modern GC-MS instruments is the simultaneous operation in full scan and SIM modes.

\subsection{Tandem techniques}

Just as a chromatographic one-dimensional system (1 column) has resolution and sample capacity that result insufficient in the analysis of complex mixtures, a one-dimensional mass spectrometer with only 1 mass analyzer experiences limitations in resolution, sensitivity, mass range, and principally, the amount of structural information required to elucidate the molecular identity (McLafferty, 1983). Mass spectra with few signals pose a difficult task during substance identification, because valuable structural clues are obtained from the abundance and mass of product ions formed by molecular fragmentation. During the GCMS analysis of extracts obtained from biological samples, soils, or food, it is frequent to find excessive chemical noise, manifested in the presence of many substances with certain physicochemical properties similar to those of the target analyte. As a consequence, the appearance of additional spectral signals obscures the structural assignment. A successful strategy to reduce the effect of these interferences has been the increase of the method's specificity. In multidimensional or tandem spectrometry a high level of specificity is obtained by implementing spectral criteria to filter the signals. Just as an extract's clean up increases its $\mathrm{S} / \mathrm{N}$ ratio, a series of mass analyzers may include filtering steps to substantially increase an analyte's spectral S/N ratio. A first analyzer may allow the passage of only the 
analyte's characteristic ions and a second analyzer may perform the actual spectral data collection. An additional analyzer may be included between the previous ones to increase the internal energies of the filtered ions and enhance their fragmentation. This is the classical configuration of a tandem mass spectrometer: MS1, activated collisions chamber, MS2, and a detection system. They are classified into 2 main groups, according to the mass analyzers employed. Linear and quadrupole ion traps, orbitraps and FT-ICR are employed in tandem in time mass spectrometers. Ions produced in the ionization area are confined, isolated, fragmented and subsequently separated according to their $\mathrm{m} / \mathrm{z}$ values, in the same physical space (Yost, 1983). The cascade of dissociation reactions of pre-selected ions, their activation and monitoring, all take place in the same analyzer but happen as a function of time, consecutively, so that it is possible to register daughter ions, granddaughter and subsequent ions, down to (MS)n. Devices of the second type are tandem in space mass spectrometers, in which at least 2 mass analyzers are separated in space. With these spectrometers it is possible not simply the study of product ions, but also of their precursor ions, of the reactions (transitions) between 2 related ions, or monitoring neutral fragment losses (Johnson et al., 1990). The triple quadrupole (QqQ) is a tandem in space spectrometer.

\subsection{Typical mass spectra fragmentation patterns}

The fragmentation pattern $(\mathrm{m} / \mathrm{z}$ and amount, $\mathrm{I} \%$, of ions registered in a mass spectrum) reflects the manner in which an ionized molecule dissociates. This is not a random process, but a series of molecular rearrangements and scissions strongly dependent on molecular structure (nature of bonded atoms, bond strength, ring strain, etc.), spatial arrangement, ionization potential and internal energy. Fragmentation patterns are unique to individual chemical structures. Clearly discernible differences exist in the fragmentation patterns of isomers. For example, despite a qualitative similarity, the mass spectra of cis-hexatriene, trans-hexatriene 1,3-cyclohexadiene and 1,4-cyclohexadiene show differences in the intensity of molecular ion signals, and in the relative intensities of the fragment ions. For any substance, the diverse fragment ions observed in its mass spectrum are formed from molecular ions with different internal energy surpluses. The condition for the appearance of a molecular ion in the mass spectrum is that its internal energy be lower than the appearance energy of its fragment ions. Since the ionization process produces a collection of molecular ions with a distribution of excitation energies, some ions will have sufficient energy to quickly dissociate into daughter ions before reaching the detector and some other ones will remain complete during this same time period, giving rise to a spectral signal at the $m / z$ value of the substance's molecular mass. This signal intensity strongly depends on the ion's ability to delocalize (stabilize) its positive charge so that no dissociation happens during the path from the ionization chamber to the detector, which lasts $\sim 1^{-5} \mathrm{~s}$. This fact is noticed when the mass spectra of $n$-decane and naphthalene are compared. Due to the stability of naphtalene's molecular ion, there are few fragment ion signals in its spectrum and most of the total ion current is represented by the intense molecular ion signal. The decane spectrum shows a weak molecular ion signal and a homologous series of fragment ions at $m / z 29,43,57,71,85$, typical of aliphatic hydrocarbons. Dissociative ionization processes may be divided into 2 big groups: (1) simple rupture reactions (homolytic, heterolytic) and (2) rearrangement reactions, which may be molecular framework rearrangements, or rearrangements involving hydrogen transposition. The most common simple ruptures are cation formation (for example, in hydrocarbon chains), allyl and benzyl ruptures, the retro Diels-Alder reaction in cyclic monounsaturated systems, and acyl ion formation. As a general 
rule, rearrangements require less energy and are more susceptible to steric effects than simple ruptures. A comparison of mass spectra of the same substance, obtained with $70 \mathrm{eV}$ or with 10 - $30 \mathrm{eV}$ electrons reveals that molecular ions and ions resulting from rearrangements and hydrogen transposition dominate the latter spectrum (Ashcroft, 1997). A compact description of the types of ions typically found in electron ionization mass spectra and the structural information that they provide is presented in Table 1.

\begin{tabular}{|c|c|c|}
\hline Ion type & Information provided & Examples \\
\hline $\begin{array}{l}\text { Molecular } \\
\text { ions }\end{array}$ & $\begin{array}{l}\text { Molecular mass. Elemental } \\
\text { composition when high resolution MS } \\
\text { is employed. Intense molecular ion } \\
\text { signals indicate that the ionic structure } \\
\text { can stabilize its positive charge and } \\
\text { this normally suggests aromaticity or } \\
\text { highly conjugated unsaturations. It is } \\
\text { common that mass spectra of branched } \\
\text { hydrocarbons, alcohols, and secondary } \\
\text { or tertiary amines are devoid of the } \\
\text { molecular ion signal. A soft ionization } \\
\text { method, such as chemical ionization } \\
\text { should be used in these cases. }\end{array}$ & $\begin{array}{l}\text { The molecular ion stability (WM) } \\
\text { is calculated as the percent } \\
\text { fraction of the total ion current } \\
\text { remaining after a substance } \\
\text { ionization and fragmentation. WM } \\
\text { for hexane, hexene and } 1,3- \\
\text { cyclodiene is } 2,8,4,6 \text { and } 16,5 \% \text {, } \\
\text { respectively. It is } 33,2 \% \text { for } \\
\text { benzene. That is, around one } \\
\text { third of the total ion current is } \\
\text { represented by benzene's } \\
\text { molecular ion. }\end{array}$ \\
\hline $\begin{array}{l}\text { Fragment } \\
\text { ions }\end{array}$ & $\begin{array}{l}\text { They contain the primary information } \\
\text { for molecular structure elucidation. } \\
\text { These may be cations (even electron } \\
\text { number) or radical cations (odd } \\
\text { electron number). They may result } \\
\text { from simple rupture or rearrangement. } \\
\text { Certain common fragment losses are } \\
\text { associated with the presence of specific } \\
\text { groups in the molecule. }\end{array}$ & $\begin{array}{l}\text { Alcohol molecular ions easily } \\
\text { decay with the loss of either an } \\
\text { OH group or an } \mathrm{H}_{2} \mathrm{O} \text { molecule, } \\
\text { giving rise to the (M-17) })^{+} \text {and (M- } \\
18)^{+} \text {ions. Fragment ions } \mathrm{C}_{6} \mathrm{H}_{5}{ }^{+} \\
\text {and } \mathrm{C}_{7} \mathrm{H}_{7}+\text { dissociate with the loss } \\
\text { of an acetylene molecule }\left(\mathrm{C}_{2} \mathrm{H}_{2}\right) \\
\text { and the generation of signals at } \\
m / z 51 \text { and } 65 \text {, respectively. }\end{array}$ \\
\hline $\begin{array}{l}\text { Isotopic } \\
\text { ions }\end{array}$ & $\begin{array}{l}\text { The substance's elemental composition } \\
\text { is derived from the relative abundance } \\
\text { of isotopic ions. The presence of } \mathrm{Cl}, \mathrm{Br} \text {, } \\
\mathrm{S} \text { or Si can be easily determined from } \\
\text { the isotopic peak pattern. A quality } \\
\text { requirement of a mass spectrum is the } \\
\text { clear distinction of isotopic ions. }\end{array}$ & $\begin{array}{l}\text { The isotopic distribution pattern } \\
\text { permits congener distinction in } \\
\text { the analysis of polychlorinated } \\
\text { biphenyls (PCB). The successive } \\
\text { loss of chlorine atoms and the } \\
\text { formation of the corresponding } \\
\text { (M-nCl)+ fragments } \\
\text { distinguishes individual } \\
\text { congeners. }\end{array}$ \\
\hline $\begin{array}{l}\text { Multiply } \\
\text { charged } \\
\text { ions }\end{array}$ & $\begin{array}{l}\text { They are found in the mass spectra of a } \\
\text { limited class of substances, for } \\
\text { example, those containing heteroatoms } \\
\text { (N, S, O), aromatic or heteroaromatic } \\
\text { rings, high unsaturation level, or when } \\
\text { several of these elements are combined } \\
\text { in the molecule. }\end{array}$ & $\begin{array}{l}\text { Their intensity is relatively low } \\
\text { and may have fractional values. } \\
\text { The signal at } m / z 64 \text { in the } \\
\text { naphthalene mass spectrum }\left(\mathrm{M}^{+},\right. \\
m / z 128) \text { corresponds to a doubly } \\
\text { charged molecular ion, } \mathrm{M}^{2+} \text {. In } \\
\text { pyrene's mass spectrum the signal } \\
\text { at } m / z 101 \text { corresponds to its } \\
\text { doubly charged molecular ion. }\end{array}$ \\
\hline
\end{tabular}




\begin{tabular}{|c|c|c|}
\hline Ion type & Information provided & Examples \\
\hline $\begin{array}{l}\text { Metastable } \\
\text { ions }\end{array}$ & $\begin{array}{l}\text { Formed out of the ionization chamber } \\
\text { from ions with life time longer than a } \\
\text { microsecond, but less than the time } \\
\text { required to reach the detector. } \\
\text { Their apparent mass } \mathrm{m}^{*} \text { ( } \mathrm{a} \text { fractional } \\
\text { number) relates the masses of parent } \\
\left(\mathrm{m}_{1}\right) \text { and daughter }\left(\mathrm{m}_{2}\right) \text { ions } \\
\text { according to } \mathrm{m}^{*}=\mathrm{m}_{2}^{2} / \mathrm{m}_{1} \text {. } \\
\text { Metastable ions are frequently } \\
\text { encountered in mass spectra } \\
\text { obtained with magnetic sector } \\
\text { analyzers. }\end{array}$ & $\begin{array}{l}\text { A mass spectrum of benzoic } \\
\text { acid contains } \mathrm{m}^{*} \text { signals } \\
\text { corresponding to processes of } \\
\text { successive loss of radical } \mathrm{OH} \text { and } \\
\text { the } \mathrm{CO} \text { molecule: } \\
\mathrm{M}^{+} \rightarrow(\mathrm{M}-\mathrm{OH})^{+} \text {and } \\
(\mathrm{M}-\mathrm{OH})^{+} \rightarrow[(\mathrm{M}-\mathrm{OH})-\mathrm{CO}]^{+} \text {. } \\
\text { These signals confirm the } \\
\text { genetic link between these ions. } \\
\text { The absence of an } \mathrm{m}^{*} \text { ion } \\
\text { corresponding to the direct } \\
\text { process } \mathrm{M}^{+} \rightarrow(\mathrm{M}-\mathrm{COOH})^{+} \\
\text {indicates that this process } \\
\text { does not take place. }\end{array}$ \\
\hline
\end{tabular}

Table 1. Typical ion types and the structural information they provide.

\subsection{Compound identification procedure}

Two fundamental strategies are employed in GC-MS for compound identification. The first one consist of comparing the unknown substance's chromatographic (retention indices) and spectroscopic (mass spectra) data against those of certified standard substances. However, in the field of natural products research, many standards are not available. The second strategy combines several approaches: (a) retention indices obtained on stationary phases with orthogonal polarity, together with (b) experimental mass spectra (EI, $70 \mathrm{eV}$ ) are compared with (c) published data compiled in databases. The identification may be tentative (preliminary, presumptive) or confirmatory. Confirmation (unequivocal, positive) requires in many occasions the use of a certified standard substance. The coincidence of chromatographic (retention times, retention indices) and spectroscopic (fragmentation pattern) parameters for the problem substance and the standard constitutes a complete or confirmatory identification of a compound in a mixture. When the comparison is not made against a standard's data but against data published in specialized literature (Adams, 2007) or spectral databases (NIST, WILEY, Adams), the match of parameters is not yet an absolute identification. When a standard is not available, the problem substance must be isolated from the mixture, purified and characterized by means of spectroscopic data (UV, IR, XRD, NMR, MS, or high resolution MS). The data from each spectroscopic method provide pieces of the structural puzzle, which the researcher must solve (McLafferty \& Turecek, 1993, Silverstein et al., 2005). Nevertheless, many GC-MS analysis of essential oils and plant extracts reveal that a considerable number of components with potential interest are present in amounts so small that their isolation and purification is a formidable, practically impossible task. In these cases, as well as in those of substances whose mass spectra lack a molecular ion, important advances in characterization can be achieved with the combined use of selective detectors (GC-ECD, GC-NPD, GC-MS in SIM mode). Further advances are possible with tandem mass spectrometers (GC-QqQ) and with high resolution mass spectrometry (GC-Q-TOF). 


\section{Applications}

GC-MS Analysis of plant volatiles is the main research tool commonly employed for determining the composition of these complex mixtures. A few examples are presented next, to highlight some of the special features of the mass selective detector in the analysis of flower volatiles and essential oils.

\subsection{Flower scent analysis}

Figure 2 illustrates the experimental setup employed for in vivo and in vitro flower scent sampling and the chromatographic profiles (total ion current) obtained. A total of 40 compounds were identified in Sansevieria trifasciata flower scent and their relative amounts changed during the day. There is no single, dominant component of the scent. Aldehydes (hexanal, heptanal, heptenal, nonanal, octenal, nonadienal, decanal), alcohols, ketones (6methyl-5-hepten-2-one, 3-octen-2-one), acetates (benzyl, hexyl, octyl, 2-ethyl-1-hexyl, decenyl, decyl, dodecenyl, dodecyl and tetradecenyl), methyl and benzyl benzoate, methyl salicilate, eugenol, and cis, trans-a-farnesene, were identified as the main scent constituents.

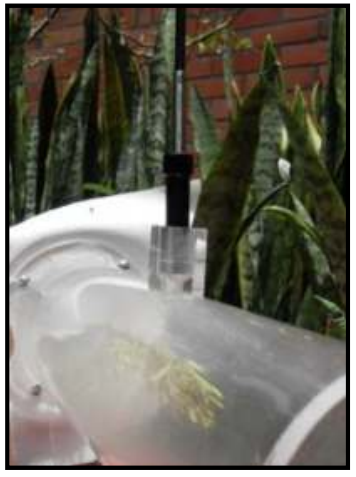

In vivo sampling

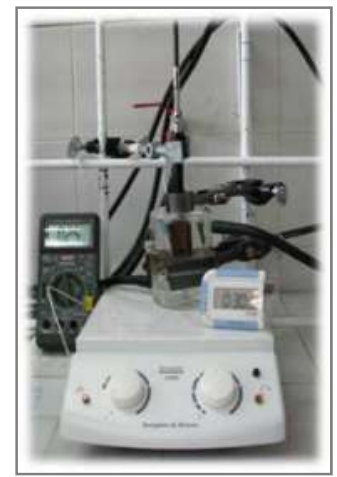

In vitro sampling

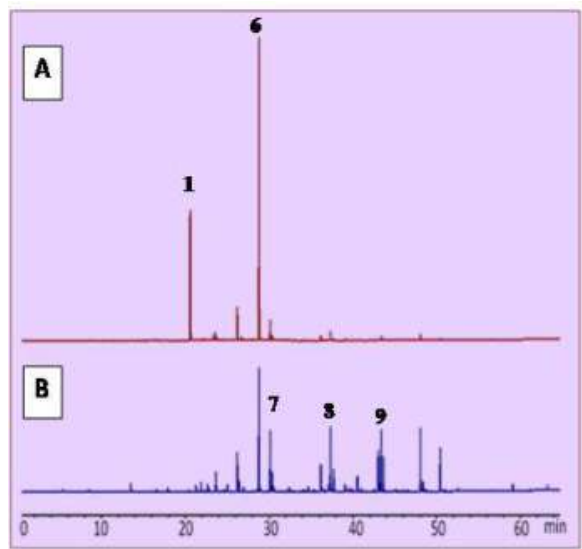

Fig. 2. Setup employed for HS-SPME sampling Sansevieria trifasciata flower scent. Typical chromatographic profiles for (A) In vivo analysis; (B) In vitro analysis. Tentative identification by comparison of mass spectra with databases. Main components: benzaldehyde (1), benzyl acetate (7), trans-3-decen-1-yl acetate, (8), and cis-7-dodecen-1-yl acetate (9).

Figure 3 contains the chromatographic profiles (GC-ECD) obtained when the carbonyl compounds were derivatized on the SPME fiber with pentafluorophenylhydrazine. The upper trace (3A) reveals the carbonyl compounds present in Sansevieria trifasciata flower scent and the lower trace (3B) shows the result obtained with a solution of homologous aliphatic aldehydes using the same on-fiber derivatization procedure. Figure $3 \mathrm{C}$ presents the results of applying principal component analysis to the composition data of all samples taken during day and night. The plane formed by the first 2 principal components permits a comparison of the compositions of Sansevieria trifasciata flower scent as a function of time. Among the samples collected at different hours, that taken at $9 \mathrm{pm}$ showed the largest difference in number of components and total chromatographic area. 


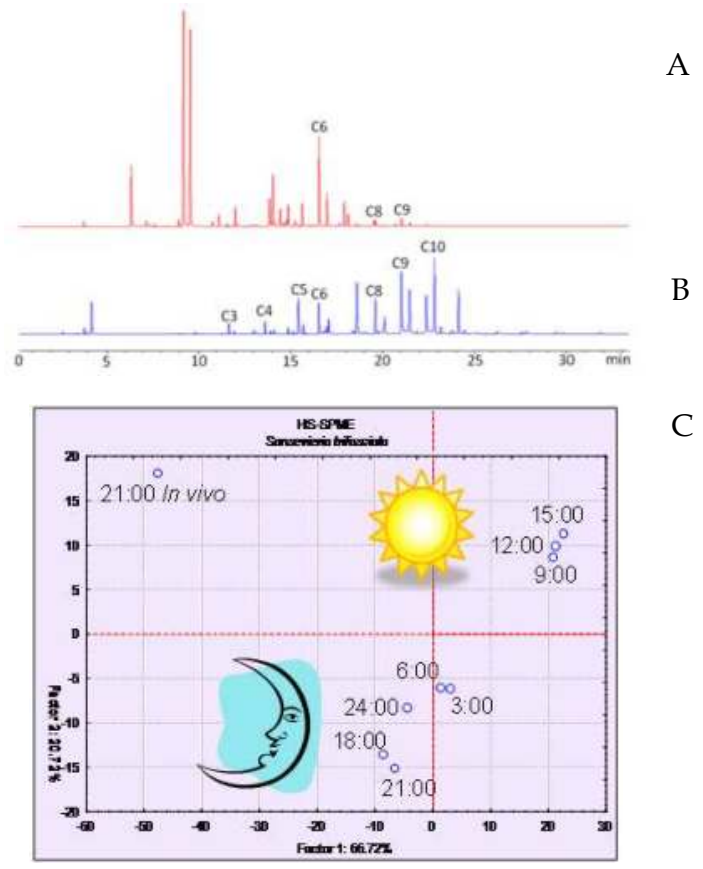

Fig. 3. Typical gas chromatographic profiles obtained after on-fibre derivatization of carbonyl compounds with pentafluorophenylhydrazine (A) from In vitro sampling of Sansivieria trifasciata flowers and (B) from a standard aqueous solution $(1,58 \mathrm{mM}$ of each aliphatic aldehyde, $\mathrm{C}_{3}-\mathrm{C}_{11}$ ). (C) Graphical representation of Sansevieria trifasciata flower scent composition change during the day. Principal component analysis of the compositional data permitted to discern a coordinate system with $87 \%$ of the information.

An important use of GC-MSD-SIM is the selective detection of a substance of interest within a complex mixture. One example is the use of GC-MSD-SIM to determine the presence of a psychotropic alkaloid, scopolamine, in a supercritical fluid (SFE, $\mathrm{CO}_{2}$ ) extract from Brugmansia suaveolens flowers. Figure 4A presents the total ion current (full scan) from the SFE flower extract. Multiple interferences, coelutions, and baseline elevation prevent the extraction of a good quality mass spectrum (Figure 4B) of the candidate component at 33.6 min. Thus, the presence of scopolamine in the extract cannot be confirmed reliably. The search in the NIST spectral database produced a scopolamine mass spectrum (Figure 4C) with characteristic signals at $m / z 303$ (molecular ion, $\mathbf{M}+$ ), 138 and 94 (base peak). These ions can be used as filters to determine scopolamine in the extract using GC-MS-SIM. Figure 4D presents the corresponding fragmentogram, interference-free, where the alkaloid is detected selectively and with much higher sensitivity than when the full scan GC-MS was used. The experimental spectrum (Figure 4E) contains the selected signals, $m / z$ 94, 138 and 303, with the same intensity relations observed in the mass spectrum of the reference substance (Figure 4C). This example illustrates an advantage of the SIM acquisition mode for the selective and sensitive (10 to 100 times higher) detection of a substance of interest in a complex mixture. Scopolamine quantitation and its confirmatory identification would require the use of a certified standard. 

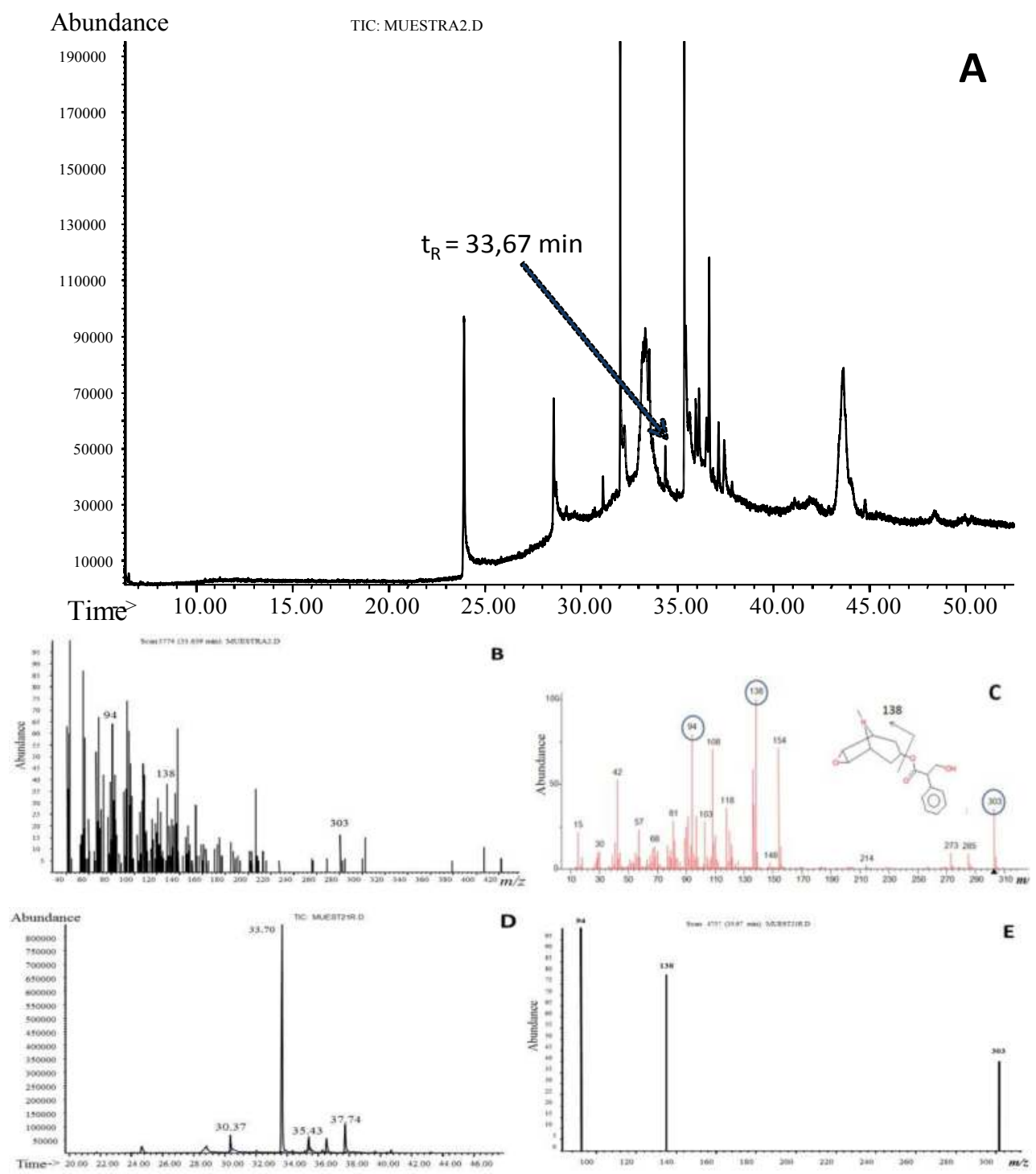

Fig. 4A. Total ion current (chromatogram) of the SFE $\mathrm{CO}_{2}$ extract of Brugmansia suaveolens flowers. 4B. Mass spectrum corresponding to the chromatographic peak with retention time of 33,64 min. Poor quality spectrum with large amount of noise. 4C. The scopolamine mass spectrum available at the NIST spectral database. 4D. Mass fragmentogram of the same Brugmansia suaveolens flower extract, obtained with GC-MS-SIM using the selected diagnostic ions for scopolamine, i. e. $\mathrm{m} / \mathrm{z} 303,138$ and 94 . $4 \mathrm{E}$. The experimental spectrum for the chromatographic peak at 33,64 min. The intensity ratios of these signals are the same as those in the mass spectrum of reference (4C). 


\subsection{Essential oil analysis}

Lippia alba (Verbenaceae family) is an aromatic shrub that grows in Central and South America. The carvone- and citral-rich chemotypes of this plant are found in Colombia. Plant development, cultivation conditions, plant part, post-harvest treatment, and extraction time are some factors which affect essential oil composition. Freshly collected or dried young and mature leaves and flowers of both $L$. alba chemotypes grown in an experimental garden were subjected to microwave-assisted hydrodistillation for 30, 45, 60, and $90 \mathrm{~min}$. GC-MS (Agilent Technologies 6890 Plus/5973/5975, DB-5MS and DB-WAX $60 \mathrm{~m} \times 0,25 \mathrm{~mm}$, D.I columns) analysis of the resultant oils showed large variations in composition. Figure 5 summarizes the composition variations registered as a function of extraction time and plant age. Carvone relative amount varied between 28,9 and $53,9 \%$, while citral relative amount changed from 22,5 to $89,2 \%$ in the oils of the 2 chemotypes, respectively. Dried young leaves (3 weeks), afforded the oil with the largest carvone yield after $30 \mathrm{~min}$ of hydrodistillation. For the other chemotype, the largest citral yield was obtained from dry young leaves (3 weeks) after 90 minutes of hydrodistillation. These oils are interesting raw materials for carvone and citral isolation, which are extensively used as flavoring agents and as starting materials in fine organic synthesis.
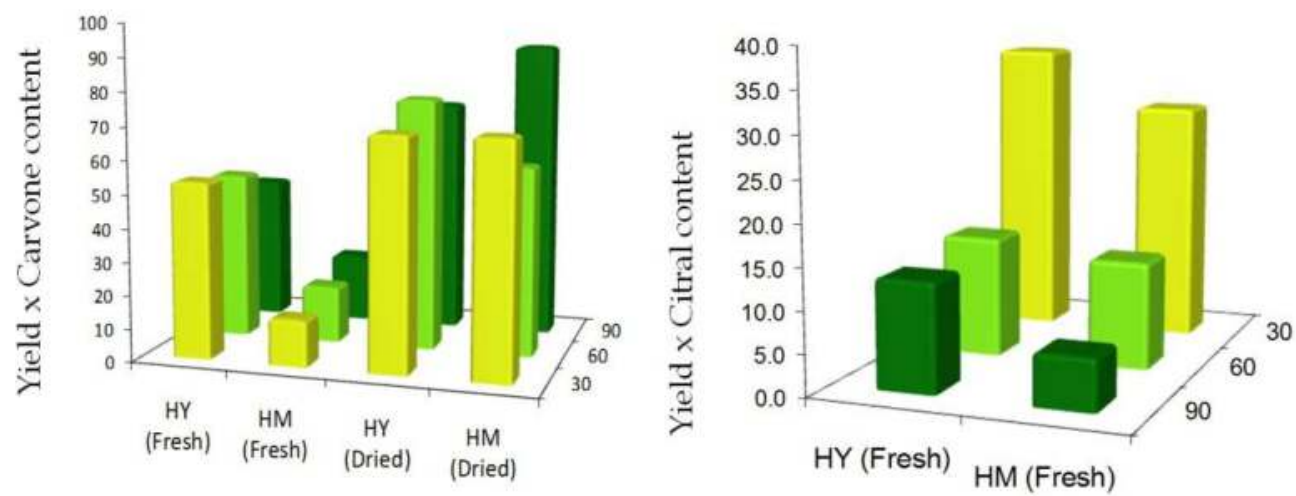

Fig. 5. (A)Variation of the product of carvone content (\%) and essential oil extraction yield, with distillation time and vegetal material maturity and moisture, for the carvone-rich Lippia alba chemotype. (B)Variation of the product of citral content (\%) and essential oil extraction yield, with distillation time and vegetal material state, for the citral-rich Lippia alba chemotype. 


\section{References}

Abhilash, P.; Singh, V. \& Singh, N. (2009). Simplified Determination of Combined Residues of Lindane and Other $\mathrm{HCH}$ Isomers in Vegetables, Fruits, Wheat, Pulses and Medicinal Plants by Matrix Solid Phase Dispersion (MSPD) Followed by GC-ECD. Food Chem., Vol.113, pp. 267-271, ISSN 03088146.

Adahchour, M.; Beens, J. \& Brinkman, U. (2008). Recent Developments in the Application of Comprehensive Two-Dimensional Gas Chromatography. J. Chromatogr. A, Vol.1186, pp. 67-108, ISSN 00219673.

Adams, R. (2004). Identification of Essential Oil Components by Gas Chromatography/Mass Spectrometry. Allured Pub. Corp., ISBN 0931710855, Illinois, U.S.A.

Amvrazi, E. \& Tsiropoulos, N. (2009). Chemometric Study and Optimization of Extraction Parameters in Single-Drop Microextraction for the Determination of Multiclass Pesticide Residues in Grapes and Apples by Gas Chromatography Mass Spectrometry. J. Chromatogr. A, Vol.1216, N¹4, pp. 7630-7638, ISSN 00219673.

Araujo, L.; Wild, J.; Villa, N.; Camargo, N.; Cubillan, D.; Prieto, A. (2008). Determination of Anti-Inflammatory Drugs in Water Samples, by in Situ Derivatization, Solid Phase Microextraction and Gas Chromatography-Mass Spectrometry. Talanta, Vol.75, $\mathrm{N}^{\circ} 1$, pp. 111-115, ISSN 00399140.

Ashcroft A. (1997). Ionization Methods in Organic Mass Spectrometry. Royal Society of Chemistry, ISBN 0854045708, Cambridge.

Babushok, V. \& Zenkevich, I. (2009). Retention Indices for Most Frequently Reported Essential Oil Compounds in GC. Chromatographia, Vol.69, N³-4, pp. 257-269, ISSN 0009-5893.

Bagheri, H.; Babanezhad, E. \& Khalilian, F. (2009). An Interior Needle Electropolymerized Pyrrole-Based Coating for Headspace Solid-Phase Dynamic Extraction. Anal. Chim. Acta, Vol.634, pp. 209-214, ISSN 00032670.

Barceló, D. (2008). Advanced MS Analysis of Metabolites and Degradation Products. Trends Anal. Chem., Vol.27, N¹0, pp. 805-806, ISSN 01659936.

Bicchi, C.; Cordero, P. \& Rubiolo, P. (2004). A Survey on High-Concentration Capability Headspace Sampling Techniques in the Analysis of Flavors and Fragrances. J. Chromatogr. Sci., Vol.42, pp. 402-409, ISSN 00219665.

Bicchi, C.; Cordero, C.; Liberto, E.; Rubiolo, P.; Sgorbini, B.; David, F. \& Sandra, P. (2005). Dual-Phase Twisters: A New Approach to Headspace Sorptive Extraction and Stir Bar Sorptive Extraction. J. Chromatogr. A, Vol.1094, pp. 9-16, ISSN 00219673.

Campillo, N.; Peñalver, R. \& Hernández, M. (2010). Determination of Dimethylselenide And Dimethyldiselenide in Milk and Milk By-Products by Solid-Phase Microextraction and Gas Chromatography With Atomic Emission Detection. Talanta, Vol.80, pp. 1856-1861, ISSN 00399140.

Chaintreau, F. (2001). Simultaneous Distillation-Extraction: from Birth to Maturity-Review. Flav. Fragr. J. Vol.16, pp. 136-148, ISSN 10510281. 
D’Acampora, B.; Bicchi, C.; Dugo, P.; Rubiolo, P.; Dugo, G. \& Mondello, L. (2008). Linear Retention Indices in Gas Chromatographic Analysis: A Review. Flav. Fragr. J., 23, pp. 297-314, ISSN 10510281.

D'Alessandro, M. \& Turlings, T. (2006). Advances and Challenges in the Identification of Volatiles that Mediate Interactions Among Plants and Arthropods. Analyst, Vol.131, pp. 24-32, ISSN 0003-2654.

Fontana, R., Patil, S., Banerjee, K., \& Altamirano, J. (2010). Ultrasound-Assisted Emulsification Microextraction for Determination of 2,4,6-Trichloroanisole in Wine Samples by Gas Chromatography Tandem Mass Spectrometry. J. Agric. Food Chem., Vol.58, N8, pp. 4576-4578, ISSN 15205118.

Fritz, J. (1999). Analytical Solid-Phase Extraction. Wiley-VCH, ISBN 9780471246671, New York.

Gan, J.; Papiernik, S.; Koskinen, W. \& Yates, S. (1999). Evaluation of Accelerated Solvent Extraction (ASE) For Analysis of Pesticide Residues in Soil. Environ. Sci. Technol., Vol.33, pp. 3249-3253, ISSN 0013936X.

Hayward, T. \& Thurbide, K. (2009). Quenching-Resistant Multiple Micro-Flame Photometric Detector for Gas Chromatography. Anal. Chem., Vol.81, N²1, pp. 8858-8867, ISSN 01659936.

Hayward, D. \& Wong, J. (2009). Organohalogen and Organophosphorous Pesticide Method for Ginseng Roots A Comparison of Gas Chromatography-Single Quadrupole Mass Spectrometry with High Resolution Time-of-Flight Mass Spectrometry Anal. Chem., Vol.81, pp. 5716-5723, ISSN 0003-2700.

Huang, B.; Qiu, L.; Chu, Q.; Zhang, Q.; Gao, L. \& Zheng, H. (2009). Comparison of Headspace SPME with Hydrodistillation and SFE for Analysis of the Volatile Components of the Roots of Valeriana officinalis var. Latifolia. Chromatographia, Vol.69, pp. 489-496, ISSN 00095893.

Hübschmann, H., (2009). Handbook of GC/MS: Fundamentals and Applications, 2a Ed. WileyVCH, ISBN 978-3-527-31427-0, Weinheim, Germany.

Johnson, J.; Yost, R.; Kelley, P. \& Bradford, D. (1990). Tandem-In-Space and Tandem-InTime Mass Spectrometry: Triple Quadrupoles and Quadrupole Ion Traps. Anal. Chem. Vol.62, N²0, pp. 2162-2172, ISSN 0003-2700.

Kaanta, B.; Chen, H. \& Zhang, X. (2010). A Monolithically Fabricated Gas Chromatography Separation Column with an Integrated High Sensitivity Thermal Conductivity Detector. J. Micromech. Microeng. Vol.20, N5, pp. 1-6, ISSN 09601317.

Kingston, H. \& Jassie, L. (1988). Introduction to Microwave Sample Preparation. American Chemical Society, ISBN 0841214506,Washington.

Kingston, H. \&. Haswell, S. (1997). . Microwave-Enhanced Chemistry: Fundamentals, Sample Preparation, and Applications. American Chemical Society, ISBN 9780841233751, Washington.

Koning, S.; Janssen, H. \& Brinkman, U. (2009). Modern Methods of Sample Preparation for GC Analysis. Chromatographia, Vol.69, NS1, pp. 33-78, ISSN 00095893. 
Kovàts, E. (1958). Gas-chromatographische Charakterisierung organischer Verbindungen. Teil 1: Retentionsindices aliphatischer Halogenide, Alkohole, Aldehyde und Ketone. Helv. Chim. Acta, Vol.41, pp. 1915-1932, ISSN 0018-019X.

Kovàts, E. (1965). Gas Chromatographic Characterization of Organic Substances in the Retention Index System. Adv. Chromatogr., Vol.1, pp. 229-247, ISSN 00652415.

Lewis, C.; Hamilton, J.; Rhodes, C.; Halliday, J.; Bartle, K.; Homewood, P.; Grenfell, R.; Goodye, B.; Harlinge, A.; Brewer, P.; Varghae, G. \& Milton, M. (2010). Microfabricated Planar Glass Gas Chromatography with Photoionization Detection. J. Chromatogr. A, 1217, pp. 768-774, ISSN 0021-9673.

McLafferty F., (1983). Tandem mass spectrometry, John Wiley and Sons, ISBN 0471865974, New York.

McLafferty, F. \& Turecek, F. (1993). Interpretation of Mass Spectra. University Science Books, ISBN 0935702253, New York.

McMaster, M. \& McMaster, C. (1998). GC/MS A Practical User's Guide, Wiley-VCH, ISBN 0471248266, New York.

Marriot, P.; Shellie, R. \& Cornwell. C. (2001). Gas Chromatographic Technologies for the Analysis of Essential Oils. J. Chromatogr. A. Vol.936, pp. 1-22, ISSN 00219673.

Marsman, J.; Wildschut, J.; Evers, P.; de Koning, S. \& Heeres, H.J. (2008). Identification and Classification of Components in Flash Pyrolysis Oil and Hydrodeoxygenated Oils by Twodimensional Gas Chromatography and Time-of-Flight Mass Spectrometry. J. Chromatogr. A, Vol.1188, pp. 17-25, ISSN 00219673.

Marsman, J.; Wildschut, J.; Evers, P.; Koning, S.; Janssen, H. \& Brinkman, U. (2009). Modern Methods Of Sample Preparation For GC Analysis. Chromatographia, Vol.69, pp. S33S78, ISSN 00095893.

Mondello, L.; Tranchida, P.; Dugo, P. \& Dugo, G. (2008). Comprehensive Two-Dimensional Gas Chromatography-Mass Spectrometry: A Review Mass Spectrom. Rev., Vol.27, pp. 101-124, ISSN 02777037.

Musshoff, F.; Lachenmeier, D.; Kroener, L. \& Madea, B. (2003). Automated Headspace SolidPhase Dynamic Extraction for the Determination of Cannabinoids in Hair Samples. Forensic Sci. Int., Vol.133, pp. 32-38, ISSN 03790738.

Mustafa, A. \& Turner, C. (2011). Pressurized Liquid Extraction As a Green Approach in Food and Herbal Plants Extraction: A Review. Anal. Chim. Acta. Vol.703, pp.8-18, ISSN 00032670.

Novák, J. (1988). Quantitative Analysis by Gas Chromatography, 2d Ed., Marcel Dekker, ISBN 0824778189, New York.

Rice, S. \& Mitra, S. (2007). Microwave-Assisted Solvent Extraction of Solid Matrices and Subsequent Detection of Pharmaceuticals and Personal Care Products (Ppcps) Using Gas Chromatography-Mass Spectrometry. Anal. Chim. Acta, Vol.589, Nº1, pp. 125-132, ISSN 00032670.

Robards, K.; Haddad, P. \& Jackson, J. (1994). Principles and Practice of Modern Chromatographic Methods. Academic Press, ISBN 0125895704, New York.

Sasamoto, K. \& Ochiai, N. (2010). Selectable One-Dimensional or Two-Dimensional Gas Chromatography-Mass Spectrometry with Simultaneous Olfactometry or 
Element-Specific Detection. J. Chromatogr. A, Vol.1217, pp. 2903-2910, ISSN 00219673.

Scheppers, S. (1999) Solid Phase Microextraction. A Practical Guide. Marcel Dekker, Inc., ISBN 0824770587, New York.

Shearer, R. (1992). Development of Flameless Sulfur Chemiluminescence Detection: Application to Gas Chromatography. Anal. Chem., Vol.64, pp.2192-2196, ISSN 01659936.

Shen, G. \& Lee, H. (2003). Headspace Liquid-Phase Microextraction Of Chlorobenzenes In Soil With Gas Chromatography-Electron Capture Detection. Anal. Chem. Vol.75, pp. 98-103, ISSN 02533820.

Silverstein, R., Webster, F., Kiemle, D. (2005). Spectrometric Identification of Organic Compounds. Wiley, ISBN 0471134570, New York.

Souza, A. \& Andrade, J. (2009). Development, Validation and Application of A SDME/GC-FID Methodology for the Multiresidue Determination of Organophosphate and Pyrethroid Pesticides in Water. Talanta. Vol.79, pp. 13541359, ISSN 00399140.

Stashenko, E. \& Martínez, J. (2004). Derivatization and Solid-Phase Microextraction. Trends Anal. Chem., Vol.23, pp. 553-561, ISSN 01659936.

Tholl, D.; Boland, W.; Hansel, A.; Loreto, F.; Rose, U. \& Schnitzler, J. (2006). Practical Approaches to Plant Volatile Analysis. Plant J., Vol.45, Nº4, pp. 540-560, ISSN 1365$313 X$.

Thurman, E. \& Mills, M. (1998). Solid-Phase Extraction. John Wiley and Sons, ISBN 0471 61422X, New York.

Van den Dool, H. \& Kratz, P. (1963). A Generalization of the Retention Index System Including Linear Temperature Programmed Gas-Liquid Partition Chromatography. J. Chromatogr., Vol.11, pp. 463-471, ISSN 0021-9673.

Wang, L.; Lord, H.; Morehead, R.; Dorman, F. \& Pawliszyn, J. (2002). Sampling and Monitoring of Biogenic Emissions by Eucalyptus Leaves Using Membrane Extraction with Sorbent Interface (MESI). J. Agric. Food Chem., Vol.50, N²2, pp. 6281-6286, ISSN 15205118.

Wang, F. \& Edwards, K. (2007). Separation of $\mathrm{C}_{2}$-Naphthalenes by Gas Chromatography $\times$ Fourier Transform Infrared Spectroscopy (GC $\times$ FT-IR): Two-Dimensional Separation Approach. Anal. Chem., Vol.79, pp. 106-112, ISSN 0003-2700.

Wenclawlak, B. (1992). Analysis with Supercritical Fluids: Extraction and Chromatography. Springer-Verlag, ISBN 3540554203, Berlin.

Westwood, S. (1993). Supercritical Fluid Extraction and Its Use in Chromatographic Sample Preparation. Blackie Academic, ISBN 0849371074, London.

Yinon, J. (1995). Forensic Applications of Mass Spectrometry, CRC Press, ISBN 0849315220, Boca Raton, Fl, U.S.A.

Yost, R. (1983). MS-MS: Tandem Mass Spectrometry. Spectra, Vol.9, №4, pp. 3-6, ISSN 21573751.

Zhang, Z. \& Li, G. (2010). A Review of Advances and New Developments in the Analysis of Biological Volatile Organic Compounds. Microchemical Journal. Vol.95, N², pp.127139, ISSN 10959149. 
Zuloaga, O.; Etxebarria, N.; Fernández, L. \& Madariaga, J. (1998). Comparison of ASE with MAE and Soxhlet for the Extraction of CBs in Soil Samples. Trends Anal. Chem., Vol.17, pp. 642-647, ISSN 01659936. 


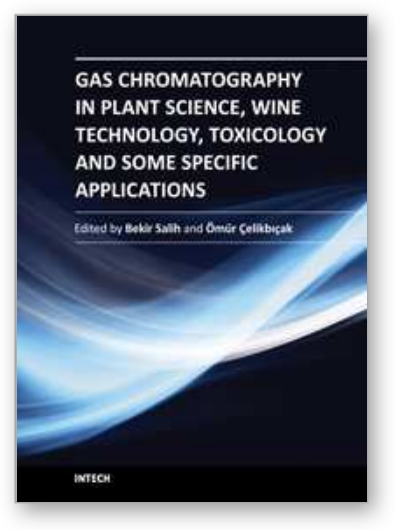

\author{
Gas Chromatography in Plant Science, Wine Technology, \\ Toxicology and Some Specific Applications \\ Edited by Dr. Bekir Salih
}

ISBN 978-953-51-0127-7

Hard cover, 346 pages

Publisher InTech

Published online 29, February, 2012

Published in print edition February, 2012

The aim of this book is to describe the fundamental aspects and details of certain gas chromatography applications in Plant Science, Wine technology, Toxicology and the other specific disciplines that are currently being researched. The very best gas chromatography experts have been chosen as authors in each area. The individual chapter has been written to be self-contained so that readers may peruse particular topics but can pursue the other chapters in the each section to gain more insight about different gas chromatography applications in the same research field. This book will surely be useful to gas chromatography users who are desirous of perfecting themselves in one of the important branch of analytical chemistry.

\title{
How to reference
}

In order to correctly reference this scholarly work, feel free to copy and paste the following:

Elena E. Stashenko and Jairo René Martínez (2012). GC-MS Analysis of Volatile Plant Secondary Metabolites, Gas Chromatography in Plant Science, Wine Technology, Toxicology and Some Specific Applications, Dr. Bekir Salih (Ed.), ISBN: 978-953-51-0127-7, InTech, Available from: http://www.intechopen.com/books/gaschromatography-in-plant-science-wine-technology-toxicology-and-some-specific-applications/gc-ms-analysisof-volatile-plant-secondary-metabolites

\section{INTECH}

open science | open minds

\author{
InTech Europe \\ University Campus STeP Ri \\ Slavka Krautzeka 83/A \\ 51000 Rijeka, Croatia \\ Phone: +385 (51) 770447 \\ Fax: +385 (51) 686166 \\ www.intechopen.com
}

\author{
InTech China \\ Unit 405, Office Block, Hotel Equatorial Shanghai \\ No.65, Yan An Road (West), Shanghai, 200040, China \\ 中国上海市延安西路65号上海国际贵都大饭店办公楼405单元 \\ Phone: +86-21-62489820 \\ Fax: +86-21-62489821
}


(C) 2012 The Author(s). Licensee IntechOpen. This is an open access article distributed under the terms of the Creative Commons Attribution 3.0 License, which permits unrestricted use, distribution, and reproduction in any medium, provided the original work is properly cited. 